\title{
Self-splicing of a group I intron reveals partitioning of native and misfolded RNA populations in yeast
}

\author{
SCOTT A. JACKSON, ${ }^{1,3}$ SUJATHA KODUVAYUR, ${ }^{1,4}$ and SARAH A. WOODSON ${ }^{2}$ \\ ${ }^{1}$ Department of Chemistry and Biochemistry, University of Maryland, College Park, Maryland 20742, USA \\ ${ }^{2}$ Department of Biophysics, Johns Hopkins University, Baltimore, Maryland 21218, USA
}

\begin{abstract}
Stable RNAs must form specific three-dimensional structures, yet many RNAs become kinetically trapped in misfolded conformations. To understand the factors that control the accuracy of RNA folding in the cell, the self-splicing activity of the Tetrahymena group I intron was compared in different genetic contexts in budding yeast. The extent of splicing was $98 \%$ when the intron was placed in its natural rDNA context, but only $3 \%$ when the intron was expressed in an exogenous pre-mRNA. Further experiments showed that the probability of forming the active intron structure depends on local sequence context and transcription by Pol I. Pre-rRNAs decayed at similar rates, whether the intron was wild type or inactivated by an internal deletion, suggesting that most of the unreacted pre-rRNA is incompetent to splice. Northern blots and complementation assays showed that mutations that destabilize the intron tertiary structure inhibited self-splicing and processing of internal transcribed spacer 2. The data are consistent with partitioning of pre-rRNAs into active and inactive populations. The misfolded RNAs are sequestered and degraded without refolding to a significant extent. Thus, the initial fidelity of folding can dictate the intracellular fate of transcripts containing this group I intron.
\end{abstract}

Keywords: RNA folding; RNA stability; metastable structure; pre-rRNA processing

\section{INTRODUCTION}

Stable noncoding RNAs must fold into specific threedimensional (3D) structures to function properly in the cell. Many RNAs misfold when transcribed in vitro, however, and the propensity to misfold is sensitive to sequence, the concentration of $\mathrm{Mg}^{2+}$ and other ions, and the rate of transcription elongation (Uhlenbeck 1995; Treiber and Williamson 1999; Woodson 2000; Pan and Sosnick 2006). Thus, maintaining the fidelity of RNA folding under intracellular conditions is critical to RNA function and evolution. An important question is whether structured RNAs must fold correctly within a certain time window after transcription, or whether misfolded RNAs or RNPs have many chances to refold before they are destroyed by nucleases.

\footnotetext{
${ }^{3}$ Present addresses: Center for Food Safety and Applied Nutrition, Food and Drug Administration, 8301 Muirkirk Road, Laurel, MD 20708, USA; e-mail: Scott.Jackson@cfsan.fda.gov. ${ }^{4}$ Department of Physiology and Biophysics, University of Illinois at Chicago, 835 S. Wolcott Avenue, Chicago, IL 60612-7342, USA; e-mail: skoduvay@uic.edu.

Reprint requests to: Sarah A. Woodson, Department of Biophysics, Johns Hopkins University, 3400 N. Charles Street, Baltimore, MD 21218, USA; e-mail: swoodson@jhu.edu; fax: (410) 516-4118.

Article published online ahead of print. Article and publication date are at http://www.rnajournal.org/cgi/doi/10.1261/rna.184206.
}

We used the self-splicing activity of the Tetrahymena group I intron to investigate the fidelity of RNA folding in yeast. Self-splicing depends only on the 3D structure of the RNA and the availability of $\mathrm{Mg}^{2+}$ and GTP (Cech 1990). Thus, the level of splicing reflects the amount of correctly folded RNA. In Tetrahymena thermophila, the intron is located in the large subunit (26S) rRNA and self-splices early during pre-rRNA processing (Cech and Rio 1979; Din et al. 1979), with an apparent $t_{1 / 2} \sim 2 \mathrm{sec}$ (Brehm and Cech 1983). The Tetrahymena intron was similarly reactive when inserted into the Escherichia coli 23S (Zhang et al. 1995) or yeast 25S rRNA (Lin and Vogt 1998). In contrast, splicing is 20-200 times slower in vitro $\left(t_{1 / 2}=0.7-7 \mathrm{~min}\right)$ because up to $95 \%$ of the pre-rRNA misfolds when transcribed in vitro (Bass and Cech 1984; Emerick and Woodson 1993). The misfolded intermediates are stable and refold slowly at $30^{\circ} \mathrm{C}$, limiting the observed rate of self-splicing (Emerick et al. 1996).

The greater activity of the Tetrahymena intron in vivo is probably not due to greater stability of its tertiary structure, as experiments on the $t d$ group I intron in E. coli (Brion et al. 1999) and the hairpin ribozyme in yeast (Donahue et al. 2000) showed that the catalytic function and thermodynamic stability of these ribozymes are similar in the cell and in "physiological" buffers. A more likely explanation is that a larger fraction of the pre-rRNA forms the active conformation in the cell than in typical in vitro 
experiments. For example, mutations that increase misfolding of the Tetrahymena pre-rRNA in vitro have a much milder effect on splicing in E. coli (Nikolcheva and Woodson 1999). This may be because fewer transcripts misfold initially, or because misfolded RNAs are rapidly refolded by RNA chaperones. A number of RNA-binding proteins and DEAD-box ATPases have the potential to stimulate RNA refolding and strand exchange reactions (Schroeder et al. 2004). For example, overexpression of E. coli StpA stimulates splicing of the $t d$ group I intron in E. coli and is able to resolve misfolded RNAs as long as the native structure is thermodynamically stable (Waldsich et al. 2002; Grossberger et al. 2005).

To dissect the factors contributing to the fidelity of RNA folding in the cell, we compared the self-splicing activity of the Tetrahymena intron in various genetic contexts in yeast. The results are best explained by the partitioning of newly transcribed pre-rRNAs into active and inactive pools, as we proposed previously for pre-rRNAs expressed in E. coli (Koduvayur and Woodson 2004). The probability of forming the active ribozyme is greatest when the intron is integrated into the chromosomal rDNA repeats of yeast, and lowest when it is placed at the $5^{\prime}$ end of a pre-mRNA transcribed by RNA polymerase II.

\section{RESULTS}

\section{In vivo splicing is linked to rRNA}

To determine which factors in eukaryotic cells favor folding of a highly structured RNA, we compared the self-splicing activity of the $T$. thermophila intron in different precursors in yeast (Fig. 1A). The 413 nucleotides (nt) intron is inserted after helix 69 in the large subunit rRNA (position 1925 , E. coli numbering), a conserved region of the large subunit rRNA that directly contacts the small ribosomal subunit (Cate et al. 1999).

Lin and Vogt (1998) found that the Tetrahymena intron spliced efficiently in the yeast Saccharomyces cerevisiae, when transposed into the $25 \mathrm{~S}$ rRNA gene at the position homologous to its natural splice junction in Tetrahymena. Cells remained viable when the intron was integrated into all of the chromosomal rDNA repeats, demonstrating that the spliced 25S rRNA was functional. Northern analysis of total RNA with a probe complementary to the intron revealed a large accumulation of spliced intron RNA and $<1 \%$ unspliced $25 \mathrm{~S}$ and $27 \mathrm{~S}$ pre-rRNA (Fig. 1B). When the intron sequences were cloned into a yeast plasmid expressing the full-length $35 \mathrm{~S}$ pre-rRNA from the GAL7 promoter (Fig. 1A; Nogi et al. 1991), we again observed little unspliced pre-rRNA on Northern blots (Fig. 1B).

The extent of splicing was measured with standard curves comparing the intensity of the intron and prerRNA bands with the amount of actin mRNA (see
Materials and Methods). The ratio of intron to pre-rRNA at steady state was 260:1 for the chromosomal 35S prerRNA transcribed by Pol I, and 15:1 for plasmid-encoded pre-rRNA transcribed by Pol II (Table 1). Thus, splicing is efficient in yeast when the intron sequences are inserted in the 25S rRNA gene, although the extent of splicing is greater when the pre-rRNA is expressed from the natural rDNA repeats.

As group I introns are often found in rRNA genes (Cannone et al. 2002), we next asked whether the pre-rRNA context is necessary to ensure a high level of self-splicing in yeast, by placing the intron cassette within a Pol IIexpressed pre-mRNA. The intron was fused to the $5^{\prime}$ end of a GFP coding sequence under the control of a galactoseinducible promoter (Fig. 1A), so that splicing restores the GFP reading frame. Compared with the pre-rRNAs, the GFP pre-mRNA spliced poorly, as judged by the amount of free intron on Northern blots (Fig. 1C) and weak expression of GFP protein (data not shown). These data indicated that the intron sequences are less likely to fold correctly in the GFP pre-mRNA than in the pre-rRNA. The Tetrahymena intron was reported to also splice poorly when inserted in mammalian pre-mRNAs (Hagen and Cech 1999; Long and Sullenger 1999).

\section{rRNA improves fidelity of folding}

The rRNA exons influence $5^{\prime}$-splice site recognition and the folding pathway of the intron core in vitro (Pan and Woodson 1998). The pre-rRNAs may splice better than the GAL-IVS-GFP mRNA, simply because the local sequence context of the intron is more favorable. To determine whether flanking rRNA exon sequences are sufficient for efficient splicing in yeast, we expressed minimal pre-rRNAs from a GAL promoter in yeast (Fig. 2A). These "mini-prerRNAs" contained 146 nt of rRNA upstream of the $5^{\prime}$ splice site and $86 \mathrm{nt}$ downstream from the $3^{\prime}$-splice site, corresponding to the minimal rRNA sequences necessary for optimal self-splicing activity in vitro (Woodson 1992). The mini-pre-rRNAs spliced three times more than the IVS-GFP pre-mRNA, when the flanking rRNA was taken from the Tetrahymena $26 \mathrm{~S}$ gene, and about the same when the rRNA was from yeast (Fig. 2B; Table 1). However, the mini-pre-rRNAs were three to five times less active than the full $35 \mathrm{~S}$ pre-rRNA expressed from the GAL promoter (Fig. $2 \mathrm{~B}$; Table 1). Thus, the sequence or structure of the rRNA surrounding the intron is important, but factors involved in rRNA transcription and ribosome biogenesis likely also increase the propensity of the intron RNA to fold and selfsplice.

\section{A pool of inactive pre-RNA}

The amount of each RNA at steady state depends on turnover of the pre-RNA and intron, as well as the rate of 
A

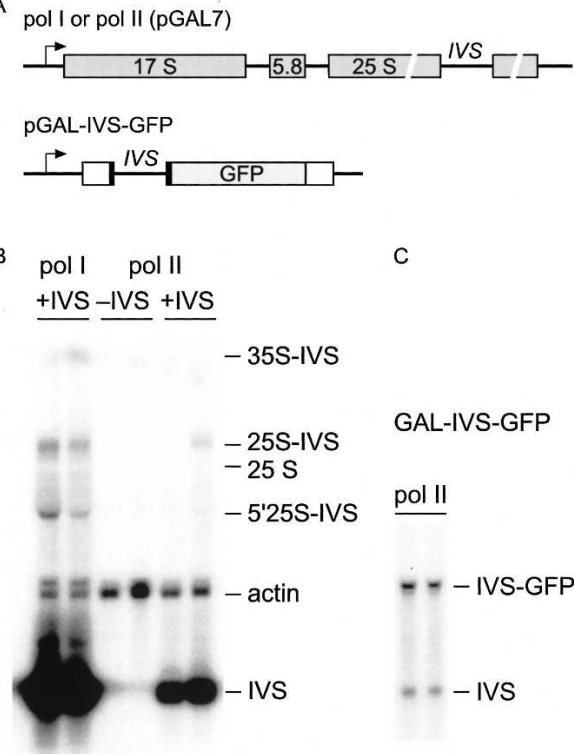

FIGURE 1. Splicing of the Tetrahymena intron in yeast. $(A$, top $)$ Chromosomal rDNA from yeast strain INVSc-TtLSU1 (Nogi et al. 1991) transcribed by RNA Pol I; pre-rRNA in pNOY102-IVS, transcribed from the GAL7 promoter (Lin and Vogt 1998). The 413-nt Tetrahymena intron was inserted in the 25S rRNA at the position homologous to the natural splice junction. The rRNA sequences flanking the intron are identical in Tetrahymena and yeast, preserving the splice sites. ( $A$, bottom) GAL1-IVS-GFP expression cassette in pSJ831. (B) Northern blot of total RNA isolated from yeast expressing the Tetrahymena intron in $35 \mathrm{~S}$ pre-rRNA from a Pol I promoter (INVSc-TtLSU1) or a Pol II promoter (pNOY102-IVS). Results for two independent yeast transformants are shown for each RNA. Membranes were hybridized with ${ }^{32} \mathrm{P}$-labeled probes specific for the intron and yeast ACT1. (IVS) Spliced intron; (5'25S-IVS) product of $3^{\prime}$-splice site hydrolysis. (C) Northern blot of yeast total RNA from two strains transformed with pSJ831 and expressing IVS-GFP mRNA, with an intron probe.

splicing. To determine whether the differences we observed are due to a difference in the splicing rate, we measured the half-lives of the spliced intron RNA and each pre-rRNA after inhibition of $G A L$ transcription by glucose at $30^{\circ} \mathrm{C}$ (Parker et al. 1991). Addition of glucose inhibits the expression of GAL genes within 1-2 min (Ronen and Botstein 2006). The amount of intron or pre-rRNA remaining at various intervals after glucose shutoff was fit to a first-order rate equation (Fig. 3). The free intron had a half-life of 46-50 $\min \left(k_{d, \mathrm{IVS}}=0.015 \mathrm{~min}^{-1}\right)$ (Figs. 2C, 3C). Electrophoresis on polyacrylamide gels showed that nearly all of the free intron RNA was linear and full length (data not shown).

The observed half-life of the pre-rRNA depends on the rate constants for splicing and nucleolytic degradation, $k_{d \text {,pre }}($ obs $)=k_{\mathrm{sp}}+k_{d \text {,pre. }}$ Thus, highly active pre-RNAs should have a shorter half-life than inactive pre-RNAs, and the rate of splicing can be determined by comparing the half-lives of active and "dead" mutant pre-rRNAs (Donahue and Fedor 1997). The observed half-life of the 25S-27S pre-rRNA containing the wild-type intron was $\sim 10$ $\min \left(k_{d, \text { pre }}=0.07-0.1 \mathrm{~min}^{-1}\right)$ (Fig. 3C). To measure the rate of degradation $\left(k_{d, \text { pre }}\right)$, we deleted $45 \mathrm{nt}$ from the catalytic core of the intron ( $\Delta$ core) to block splicing (Fig. $3 \mathrm{~B})$ ). Surprisingly, the "dead" $\Delta$ core pre-25S rRNA disappeared at nearly the same rate as pre-25S rRNA containing the wildtype intron, within the error of the experiment (Fig. 3C). This result was inconsistent with rapid splicing of the prerRNA at steady state. Instead, we concluded that the residual unspliced pre-rRNA represents a population that is incompetent to splice and that is primarily turned over by cellular nucleases.

The half-lives of mini-pre-rRNAs containing the wildtype intron or an inactive G-site mutant (G264A) were also similar to each other ( 0.2 versus $0.015 \mathrm{~min}^{-1}$ ) (Fig. $2 \mathrm{C})$. The difference in the decay rates of the wild-type and mutant pre-rRNAs yield an apparent splicing rate of $0.05 \mathrm{~min}^{-1}$, if one assumes that all of the wild-type transcripts have the same potential to self-splice. This apparent splicing rate, however, is slower than refolding

TABLE 1. Splicing of Tetrahymena intron in yeast

\begin{tabular}{lccccc}
\hline pre-RNA & [IVS]/[pre] & $f_{\text {IVS }}$ & [pre]/[actin] & $k_{d, \text { pre }}\left(\mathrm{min}^{-1}\right)$ & $\Phi$ \\
\hline $35 S$ (rDNA) ${ }^{\mathrm{a}}$ & 258 & 1.00 & 1.14 & $-{ }^{\mathrm{c}}$ & 0.98 \\
& & & & & \\
GAL-35S rRNA & 14.6 & 0.94 & 0.81 & $0.07-0.1$ & 0.76 \\
$\quad \Delta$ core & 0 & 0 & 14.6 & 0.08 & 0 \\
G100C & 0.39 & 0.28 & 5.5 & - & 0.08 \\
C260G & 0.01 & 0.01 & 16.2 & - & 0 \\
G264A & 0 & 0 & 19.1 & - & 0 \\
tri mutant ${ }^{b}$ & 0.32 & 0.24 & 3.0 & - & 0.06 \\
& & & & & \\
mini-rRNA; Tth & 3.0 & 0.75 & 1.5 & 0.18 & 0.23 \\
& & & & & \\
mini rRNA; Sce & 1.4 & 0.59 & 2.7 & 0.20 & 0.13 \\
G100C & 0 & 0 & 8.7 & 0.15 & 0 \\
C260G & 0 & 0 & 11.1 & 0.15 & 0 \\
G264A & 0 & 0 & 8.7 & 0.15 & 0 \\
tri mutant ${ }^{\mathrm{c}}$ & 0 & 0 & 8.8 & 0.15 & 0 \\
& & & & & \\
GAL-IVS-GFP & 0.53 & 0.35 & - & - & 0.03 \\
$\Delta$ core & 0 & 0 & - & 0.25 & 0 \\
\hline
\end{tabular}

The splicing parameters were measured as described in Materials and Methods: [IVS]/[pre], steady-state ratio of spliced intron to pre-rRNA; fraction spliced intron, $f_{\mathrm{IVS}}=$ (counts IVS)/[(counts IVS)+(counts pre)]; unspliced RNA relative to actin mRNA at steady-state, [pre]/[actin]=(counts pre)/(counts actin); $k_{d \text {,pre, ob- }}$ served pre-rRNA decay rate. The partition factor $\Phi$ was calculated as described in Materials and Methods, with $k_{d, \mathrm{IVS}}=0.015 \mathrm{~min}^{-1}$ and $k_{d \text {,pre }}=0.07 \mathrm{~min}^{-1}$ for GAL-35S pre-rRNAs, $0.15 \mathrm{~min}^{-1}$ for mini-pre-rRNAs, and $0.25 \mathrm{~min}^{-1}$ for GAL-IVS-GFP. The precision is $20 \%$ for [IVS]/[pre], $10 \%-15 \%$ for the decay rates, and $30 \%$ for $\Phi$. Results are the average of two to four trials. Assuming a 1-2-min delay in glucose shutoff would double decay rates for the minirRNAs, with $\Phi=0.13$ and 0.07 , respectively. This assumption would negligibly affect the splicing parameters of the other pre-RNAs.

antron integrated into chromosomal rDNA.

${ }^{\mathrm{b}} \mathrm{C} 78 \mathrm{G}, \mathrm{G} 77 \mathrm{C}$, U273A.

${ }^{\mathrm{c}}$ Not determined. 
A

pGAL mini pre-rRNA
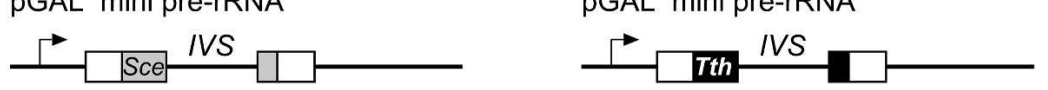

B
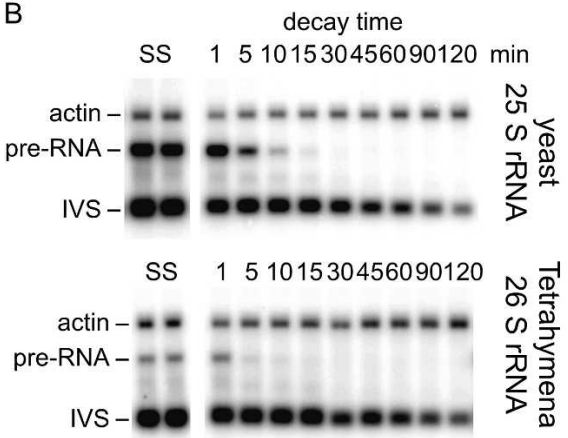

C

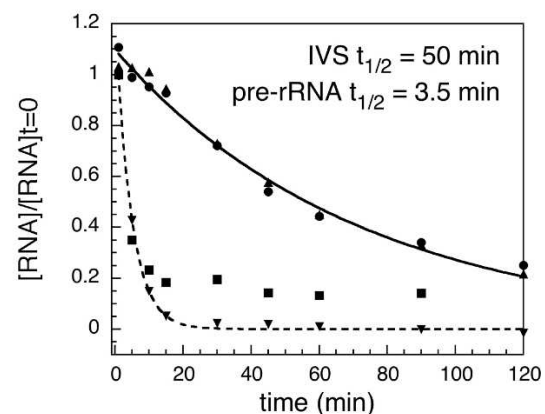

FIGURE 2. Flanking rRNA exons enhance splicing of the Tetrahymena intron in yeast. $(A)$ Plasmids for expression of minimal pre-rRNAs in yeast, with exons derived from yeast (Sce) 25S rRNA (pSJ015) or T. thermophila (Tth) 26S rRNA (pSW015). (B) Northern blot showing mini-pre-rRNA and spliced intron (IVS) at steady state (SS) and at various times after glucose inhibition of GAL transcription. (C) Decay of intron and mini-pre-rRNAs. The RNA remaining was normalized to the steady-state level prior to glucose repression. $(\bullet)$ Tth intron $\left(k_{d, \mathrm{obs}}=0.014 \mathrm{~min}^{-1}\right) ;(\boldsymbol{\Delta})$ Sce intron $\left(k_{d, \mathrm{obs}}=0.014 \mathrm{~min}^{-1}\right) ;(\boldsymbol{\square})$ Tth pre-rRNA $\left(k_{d, \mathrm{obs}}=0.18\right.$ $\left.\min ^{-1}\right) ;(\boldsymbol{\nabla})$ Sce pre-rRNA $\left(k_{d, \mathrm{obs}}=0.21 \mathrm{~min}^{-1}\right)$.

of comparable mini-pre-rRNAs in vitro $\left(0.14-0.6 \mathrm{~min}^{-1}\right)$ (Pan et al. 1999a) and too small to account for the accumulation of spliced introns in yeast. Thus, we again conclude that RNAs that remain unspliced a few minutes after transcription in yeast have very little (if any) probability of refolding.

\section{Partitioning of transcripts into active and inactive pools}

If newly transcribed pre-rRNAs form a single pool with a uniform probability of splicing, then the rate of splicing can be obtained by the intron decay rate and the ratio of intron to pre-rRNA at steady state, $k_{\mathrm{sp}}=k_{d, \mathrm{IVS}}([\mathrm{IVS}] /[\mathrm{pre}])_{\mathrm{sS}}$ (Brehm and Cech 1983). This "single-pool" model yields apparent splicing rates ranging from $0.008 \mathrm{~min}^{-1}$ for IVSGFP to $4 \mathrm{~min}^{-1}$ for chromosomally encoded pre-35S rRNA. As described above, however, this model cannot explain the very similar half-lives of the wild-type and inactivated prerRNAs. Instead, the data are better explained by partitioning of nascent transcripts into active and inactive pools, as we proposed for similar experiments in E. coli (Koduvayur and Woodson 2004).

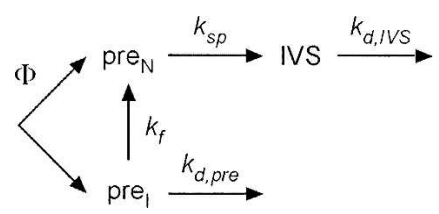

In the partitioning model, the active pre-rRNA $\left(\right.$ pre $_{\mathrm{N}}$ ) splices rapidly to produce mature rRNA and free intron, while the inactive pre-rRNA ( pre $_{\mathrm{I}}$ ) is degraded and only occasionally refolds into the active form. If we assume for simplicity that nearly all of the active pre-rRNA splices, and that splicing is much faster than refolding $\left(k_{\mathrm{sp}} \gg k_{f}\right)$, then the ratio of intron to pre-rRNA at steady state is

$$
\begin{aligned}
\frac{[\mathrm{IVS}]}{\left[\operatorname{pre}_{\mathrm{N}}\right]+\left[\mathrm{pre}_{\mathrm{I}}\right]} & \approx \frac{[\mathrm{IVS}]}{\left[\mathrm{pre}_{\mathrm{I}}\right]} \\
& \approx \frac{k_{d, p r e} \Phi}{k_{d, I V S}(1-\Phi)}
\end{aligned}
$$

in which $\Phi$ is the fraction of transcripts that fold correctly, $k_{d, \text { IVS }}$ is the intron decay rate, and $k_{d \text {,pre }}$ is the decay rate of the inactive pre-rRNA (Koduvayur and Woodson 2004). In this model, the yield of spliced 25S rRNA depends on the proportion $(\Phi)$ of transcripts that initially fold correctly, as misfolded transcripts have little chance to refold and selfsplice. Using these assumptions, we found that $\Phi=0.98$ when the intron was integrated into the chromosomal rDNA (Table 1). In contrast, few of the short Pol II pre-RNAs become active; $\Phi=0.26$ and 0.13 for mini-pre-rRNAs and $\Phi$ $=0.03$ for GFP pre-mRNA (Table 1).

\section{Partial suppression of misfolding mutations in pre-rRNA}

The results above showed that the likelihood of the intron folding into its active conformation is $76 \%-98 \%$ when it is placed within the full-length pre-rRNA, but only $3 \%-$ $26 \%$ when inserted in a short pre-mRNA transcribed by RNA Pol II. To test whether factors associated with synthesis and maturation of $35 \mathrm{~S}$ pre-rRNA enhance the fidelity of folding, we compared the phenotypes of mutations known to increase misfolding of the intron in vitro without abolishing catalytic activity (Fig. 4). Mutation of G100 to C, which stabilizes a misfolded secondary structure in the intron core (Pan and Woodson $1998)$, reduced the fraction of spliced pre-rRNA $\sim 10$-fold $(\Phi=0.08)$. A triple mutant (U273A, G77C, C78G), which is less stable than the wild type but folds more rapidly in vitro (Pan and Woodson 1999; Russell et al. 2002), also had reduced activity in yeast $(\Phi=0.06)$. Destabilization of the triple helical scaffold (C260G), which severely reduced the in vitro folding rate (Zarrinkar and Williamson 1996), almost eliminated splicing of the prerRNA in yeast. 
A

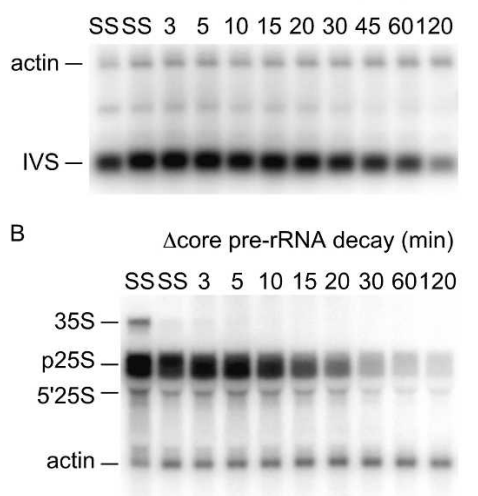

C

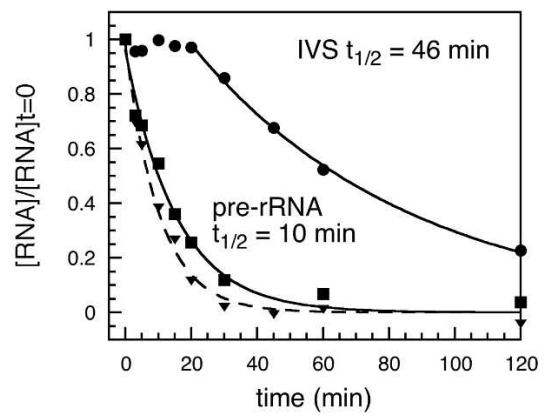

FIGURE 3. Intron and pre-rRNA stability. Northern blots of yeast total RNA with intron and actin mRNA probes, as in Figure 2. (A) Cells transformed with pNOY102 expressing GAL-35S pre-rRNA at steady state (SS) and at various times after glucose repression. (B) Stability of unspliced $35 \mathrm{~S}$ and $25 \mathrm{~S}$ pre-rRNA. Splicing is blocked by a $45-\mathrm{nt}$ deletion in the intron core ( $\Delta$ core). Cells were transformed with pNOY102-TAG-IVS- $\Delta$ P7, which contains a sequence tag in the 25S rRNA (Peculis and Greer 1998). (C) Decay of intron and pre-rRNAs, as in Figure 2. $(\bullet)$ Intron $\left(k_{d, \text { obs }}=0.017 \mathrm{~min}^{-1}\right)$; ( $) \Delta$ core pre-rRNA $\left(k_{d, \text { obs }}=0.065 \mathrm{~min}^{-1}\right)$; $(\boldsymbol{\nabla})$ wild-type pre-rRNA $\left(k_{d, \text { obs }}=0.098 \mathrm{~min}^{-1}\right)$.

Thus, splicing in yeast correlates with the stability of the RNA tertiary structure and the propensity of the intron to fold correctly. The amount of spliced product is probably not due to rapid degradation of the mutant intron RNA, as the half-lives of the wild-type and mutant introns $\left(k_{d, \mathrm{IVS}}\right)$ were very similar in E. coli at $30^{\circ} \mathrm{C}$ (Nikolcheva and Woodson 1999). We were unable to detect any spliced intron when these same mutations were introduced into the yeast mini-pre-rRNA (data not shown), although 10-20-fold less intron RNA would have been detectable in our Northern blots. The misfolded intron may be more able to recover in the full-length pre-rRNA than in mini-pre-rRNAs transcribed by Pol II, because of upstream sequences or the recruitment of ribosome assembly proteins to the $35 \mathrm{~S}$ pre-rRNA.

\section{Complementation assay for spliced 25S rRNA}

Because the intron is inserted in a conserved region of the $25 \mathrm{~S}$ rRNA, unspliced 25S rRNA is not expected to be functional. To evaluate whether misfolded mutations reduce the production of active 605 ribosomes, we determined whether plasmids expressing the $35 \mathrm{~S}$ pre-rRNA from a Pol II promoter (Fig. 1A) could complement a temperature-sensitive mutation in the large subunit of RNA Pol I (Nogi et al. 1993). At the nonpermissive temperature $\left(37^{\circ} \mathrm{C}\right)$,
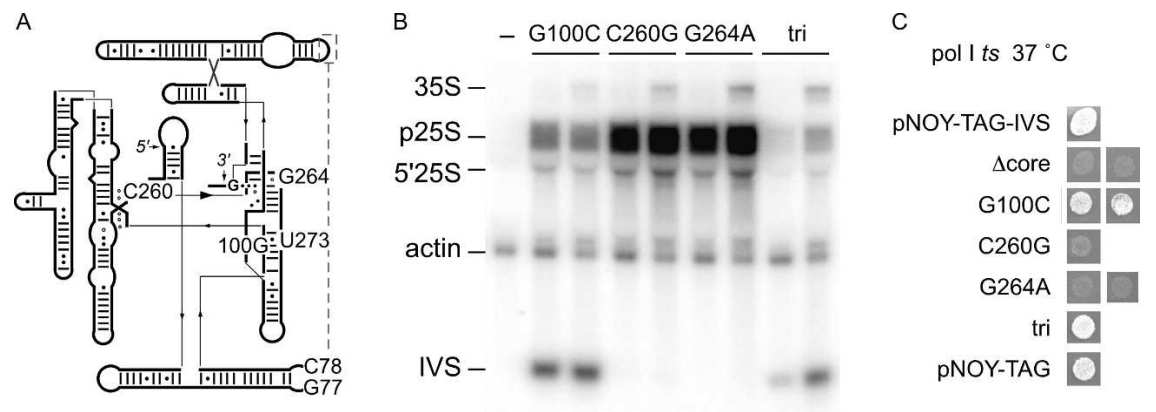

FIGURE 4. Intron misfolding inhibits splicing in yeast. (A) Schematic of intron mutations. (B) Steady-state expression of GAL-35 S pre-rRNA, containing mutations shown in $A$. (-) No intron; (tri) triple mutant C78G, G77C, U273A. RNA from two independent transformants was analyzed for each mutant. The Northern was hybridized with intron and actin probes. Bands indicate unspliced $35 \mathrm{~S}$ and $25 \mathrm{~S}$ pre-rRNAs, $5^{\prime}-25 \mathrm{~S}$-intron hydrolysis product, actin mRNA, and spliced intron (IVS). (C) Complementation of Pol I ts mutation rpa190-3 by plasmids expressing GAL-35S pre-rRNA (pNOY-TAG-IVS or pNOY-TAG). Yeast cells were spotted onto SC-galactose and replicate plates were grown at the nonpermissive temperature $\left(37^{\circ} \mathrm{C}\right)$. (Images of individual colonies were cropped from a single photograph and arranged in the figure.) 


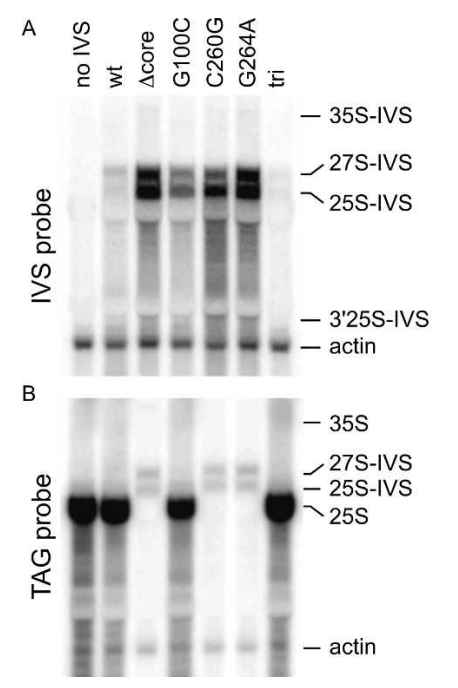

C

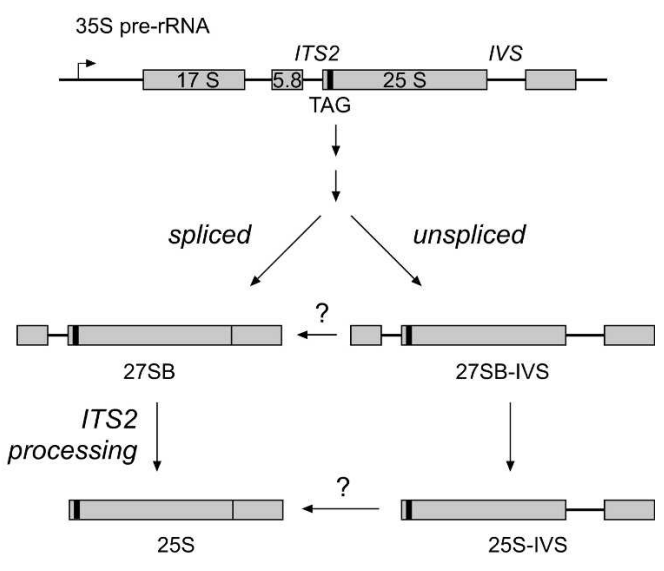

FIGURE 5. Defective splicing inhibits processing of ITS 2. Steady-state expression of GAL-35S pre-rRNA with mutations as in Figure 4A. (35S-IVS) unspliced full-length $35 \mathrm{~S}$ pre-rRNA; (27SIVS) unspliced 27SB pre-rRNAs containing ITS 2; (25S-IVS) unspliced 25S rRNA, 25S, mature rRNA, and 3'25S-IVS intron-3' -exon splicing intermediate. (A) Intron probe. (B) Probe specific for sequence tag in plasmid-encoded 25S rRNA. (C) Pre-rRNA processing in yeast leading to mature $25 \mathrm{~S}$ rRNA. Intermediate steps and alternative processing pathways are not shown. increase in the fraction of spliced $35 \mathrm{~S}$ pre-rRNA at $37^{\circ} \mathrm{C}$, for the wild-type intron, G100C, and triple mutant (Fig. 6). Very little total RNA was recovered from yeast grown at $20^{\circ} \mathrm{C}$, making lowtemperature effects difficult to quantify. Nonetheless, the inability of the G100C or $\mathrm{C} 260 \mathrm{G}$ intron to be rescued at $37^{\circ} \mathrm{C}$ suggested that more rapid refolding of misfolded intron RNA is not sufficient to ensure that the pre-rRNA is spliced in yeast. However, these results are consistent with the idea that transcripts that initially misfold have a high probability of becoming sequestered in an inactive state. The stability of the intron tertiary structure may be important for in vivo activity, as C260G is more destabilizing than the other base substitutions tested here (Pan and Woodson 1998, 1999) and is least active at all temperatures.
35S pre-rRNA, even when splicing was completely blocked by deletion of the intron core ( $\Delta$ core) (Fig. 5 ). Thus, failure to excise the intron does not inhibit early steps in prerRNA processing, but may inhibit processing of internal transcribed spacer 2 (ITS 2). Hybridization with a probe against the $25 \mathrm{~S}$ tag showed that destabilization of the intron tertiary structure (C260G) or disruption of the active site (G264A and $\Delta$ core) resulted in no detectable mature $25 \mathrm{~S}$ rRNA (Fig. 5B), consistent with the inability of these mutants to complement growth of a Pol I temperaturesensitive strain (Fig. 4C).

The unspliced pre-25S and 27S rRNAs were much less abundant than the plasmid-encoded 25S rRNA from an intron-minus control, suggesting that they are rapidly degraded. Inhibition of ITS 2 processing has been observed in response to various defects in 60S ribosome assembly (e.g., de la Cruz et al. 1998; Peculis and Greer 1998), and such defects can lead to rapid turnover of the rRNA (Allmang et al. 2000). Thus, misfolding of the intron may cause $60 \mathrm{~S}$ ribosomes to fail an important quality-control checkpoint.

\section{Temperature dependence of splicing}

Misfolded RNAs can often be rescued by refolding at higher temperatures, while mutations that favor an alternative conformation often have a cold-sensitive phenotype (e.g., Dammel and Noller 1993; Zavanelli et al. 1994). We previously found that mutations that increased misfolding of the Tetrahymena intron were less deleterious when expressed in E. coli at $42^{\circ} \mathrm{C}$ than at $25^{\circ} \mathrm{C}$ (Nikolcheva and Woodson 1999). In yeast, we observed only a modest

\section{DISCUSSION}

\section{RNA partitioning in vivo}

Many RNA sequences can fold into more than one stable structure, and the extent of misfolding is sensitive even to

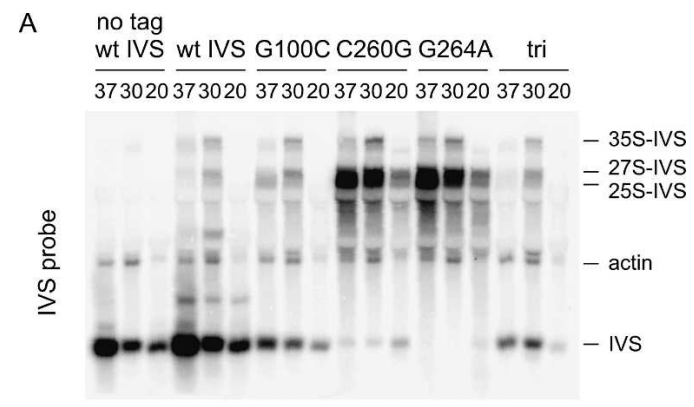

B

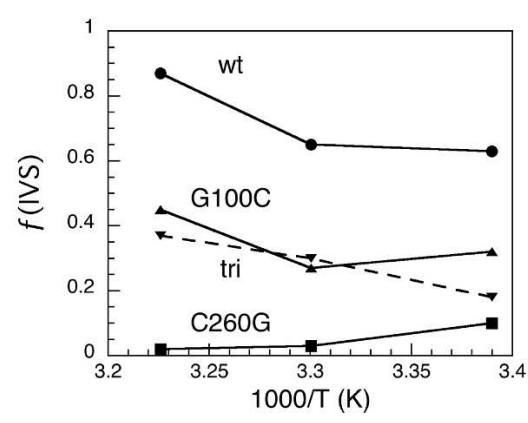

FIGURE 6. Temperature dependence of 35 S pre-rRNA splicing. (A) Transformed yeast were grown in SC-galactose at the temperatures shown above each lane, before Northern analysis as in Figure 4B. (B) The fraction of spliced intron in $A$ was obtained from (counts IVS)/ [(counts IVS+counts pre)], as described in Materials and Methods. 
single base substitutions. In vitro, RNA molecules partition among competing folding pathways, which lead either to the native or misfolded structures (Thirumalai and Woodson 1996). A number of experiments have shown that the Tetrahymena ribozyme folds through multiple pathways (Pan et al. 1997, 2000; Zhuang et al. 2000; Laederach et al. 2006). In vitro, kinetic partitioning may occur early in the folding process, perhaps when the secondary structure is formed. The results presented here suggest that transcripts also partition into active and inactive populations in yeast within a short period after they are synthesized. Because inactive pre-rRNAs are degraded without producing mature 25S rRNA, the fidelity of intron folding determines the fate of the pre-rRNA.

A key observation is that pre-RNAs that should be competent to self-splice disappear at nearly the same rate as pre-RNAs in which the intron active site is crippled or dead. These results, and the amount of spliced RNA at steady state, are best explained by assuming that most of the unspliced RNA is degraded without having a chance to refold and splice. As expected, the proportion of inactive pre-rRNA increases with intron mutations known to promote misfolding. Assuming that all pre-RNAs splice at a single rate or that misfolded RNAs are able to refold at the in vitro rate overestimates the amount of spliced RNA produced by the mutants and the mini-pre-rRNAs, as we observed previously (Koduvayur and Woodson 2004). Although our data suggested that the unspliced RNA is ultimately sequestered in an inactive state, our data do not exclude refolding of RNA domains during or just after synthesis.

\section{Cotranscriptional folding}

Early partitioning of ribozyme transcripts into functional and nonfunctional pools implies that folding, and quality control, is closely linked with RNA synthesis. This is consistent with the abundant evidence for physical and functional links between transcription and RNA splicing, polyadenylation, decay, processing, and nuclear export (Neugebauer 2002; Bentley 2005). For ribozymes and certain regulatory RNAs, the order in which RNA sequences are transcribed and the rate of elongation can determine the type of folding intermediates that are formed (e.g., Poot et al. 1997; Pan et al. 1999b; Diegelman-Parente and Bevilacqua 2002; Heilman-Miller and Woodson 2003; Granneman and Baserga 2005; Mahen et al. 2005; Wickiser et al. 2005). Therefore, one effect of transcription is to directly influence the folding pathway of the RNA.

A second effect of transcription is to deliver a specific subset of RNA-binding proteins to the nascent transcript. Many of the yeast and mammalian proteins that have been implicated in RNA folding are associated with a class of transcripts. For example, there is considerable evidence for cotranscriptional assembly and processing of pre-rRNA (Granneman and Baserga 2005), and these assembly factors are recruited to the pre-rRNA in part via Pol I (Oakes et al. 1993). The yeast La protein binds Pol III transcripts and facilitates assembly and maturation of pre-tRNAs and U6 snRNA (Fan et al. 1998; Pannone et al. 1998; Chakshusmathi et al. 2003), while Lsm 2-8 complexes associate with mRNAs (Tharun et al. 2000).

For both of these reasons, it is interesting to consider whether transcription in the cell creates a time window in which RNA domains must fold. Our data show that the probability of folding correctly in yeast (this study) and E. coli (Koduvayur and Woodson 2004) depends on which polymerase transcribed the pre-rRNA, suggesting that folding occurs cotranscriptionally. Recent experiments on the hairpin ribozyme, however, suggest that cotranscriptional folding is less important in yeast than thermodynamic stability of the active conformation (Mahen et al. 2005). A possible explanation for this difference is that the smaller hairpin ribozyme refolds more easily within an mRNA than the larger Tetrahymena ribozyme.

\section{Factors that facilitate splicing of rRNA introns}

Several factors account for the vigorous splicing of the Tetrahymena group I intron in its native context. First, the surrounding rRNA appears to favor the active conformation of the intron. Group I introns are often found in dynamic regions of the rRNA (Jackson et al. 2002), and this flexibility may allow the intron to bind the splice sites more easily. Second, factors associated with Pol I transcription and ribosome biogenesis also contribute to the propensity of the intron RNA to fold, as mini-pre-rRNAs that are not assembled into $60 \mathrm{~S}$ ribosomes splice much more poorly than full-length pre-rRNAs. In addition to ribosomal proteins, which stabilize the folded rRNA, ribosome biogenesis involves a large number of transacting factors, including many ATP-dependent RNA helicases that are capable of actively unwinding the rRNA (Kressler et al. 1999; Fatica and Tollervey 2002). Thus, in its natural context, the Tetrahymena group I intron may hitchhike on a system devoted to the folding and assembly of rRNA.

Finally, proteins that associate with Pol II transcripts, such as hnRNP proteins, may antagonize intron folding. This is supported by the fact that the Tetrahymena intron is more active in mammalian cells when transcribed by T7 RNA polymerase in the cytoplasm, than when expressed from an endogenous Pol II promoter (Byun et al. 2003). Many abundant RNP proteins contain structural motifs that preferentially bind single-stranded RNA (Dreyfuss et al. 2002), and such proteins could invade RNA domains 
that are not stably folded. In the future, it will be important to understand how intracellular proteins associated with various transcription complexes modulate RNA folding pathways.

\section{MATERIALS AND METHODS}

\section{Yeast strains}

S. cerevisiae strain INVSc2/TtLSU1 (MATa his3- 4200 ura3-167 25S::TtLSU1) has the Tetrahymena group I intron integrated into every copy of the 25S rDNA on Chromosome XII (Lin and Vogt 1998), and was the gift of V. Vogt. For splicing assays, plasmids expressing the intron were transformed into strain BY4733

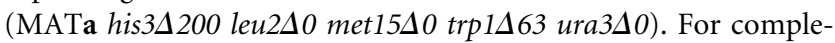
mentation assays, plasmids derived from pNOY102 were transformed into strain NOY505, which carries the rpa190-3 temperaturesensitive allele of the large subunit of RNA Pol I (Nogi et al. 1993). Transformants were isolated at $22^{\circ} \mathrm{C}$, then shifted to the nonpermissive temperature $\left(37^{\circ} \mathrm{C}\right)$ on galactose-containing media to induce expression of the plasmid-encoded $35 \mathrm{~S}$ rRNA from the GAL7 promoter.

\section{Plasmid construction}

Plasmid pSJ831 contains the Tetrahymena group I intron immediately upstream and in frame with the GFP coding sequence in the vector p423-GAL1 (Mumberg et al. 1995). Correct splicing restores the GFP reading frame and can be monitored by GFP expression. The sequence of GFP mut3.1 (Andersen et al. 1998) was amplified by PCR with primers UP-GFP (5'-GGCAAGCT TAGCGCCCAATACGCAAACCG- $3^{\prime}$ ) and DP-GFP (5'-CGCCT CGAGCTTCCGCTTCCTCGCTCACT- $3^{\prime}$ ) and ligated into the EcoRI and XhoI sites of p423-GAL1 to create pSJ431. The sequences of the Tetrahymena intron plus $15 \mathrm{nt}$ of upstream and 12 nt of downstream rRNA were amplified by PCR primers UP-IVS (5'-GCGTCTAGATGACTCTCTAAATAGCAATATTTAC- ${ }^{\prime}{ }^{\prime}$ ) and DP-IVS (5'-CCGAGATCTACCTTACGAGTACTCCAAAACTAA T-3'), and cloned into pSJ431 as an XbaI-EcoRI fragment. Expression of the intron-GFP mRNA is controlled by the GAL1GAL10 promoter and ends downstream from GFP with a CYC1 termination sequence. Inactive variants were prepared by deletion of the 45-bp BglII-NheI fragment in the intron core ( $\Delta$ core).

Plasmid pSW015 contains the Tetrahymena intron plus $146 \mathrm{nt}$ of natural $26 \mathrm{~S}$ rRNA upstream from the $5^{\prime}$-splice site and $86 \mathrm{nt}$ of rRNA downstream from the $3^{\prime}$-splice site from pSW012 (Woodson 1992). These sequences were amplified by PCR and subcloned into the BamHI and XhoI sites of p425-GAL1. Plasmid pSJ015 is the same as pSW015 except the flanking rRNA exon sequence is derived from the yeast $25 \mathrm{~S}$ rRNA, amplified from the rDNA of INVSC-TtLSU1 (Lin and Vogt 1998). Point mutations were introduced into pSJ015 by exchanging the SphI-NheI intron fragment with variants of pSW012 carrying the desired mutation (Pan and Woodson 1998).

Full-length $35 \mathrm{~S}$ pre-rRNA was expressed from pNOY102, which contains the GAL7 promoter fused to a single copy of the $35 \mathrm{~S}$ rRNA operon (6922 bp) from S. cerevisiae (Nogi et al. 1991 ) and was the gift from M. Nomura. pNOY102-Tag was the gift of B. Peculis and contains a unique 18-nt sequence tag in the $5^{\prime}$ end of the 25S rRNA (Peculis and Greer 1998). Intron sequences were inserted into pNOY102 and pNOY102-Tag by linearizing the plasmid DNA with I-PpoI. The digested DNA was treated with T4 DNA polymerase and calf intestinal phosphatase before ligation with a PCR product containing the intron plus $1 \mathrm{nt}$ of $5^{\prime}$ exon and $3 \mathrm{nt}$ of $3^{\prime}$ exon (upstream, 5'-TAAATAGCAATATTTACCTTTGGAGG; downstream, 5' -TTAC GAGTACTCCAAAACTAATCAATAT).

\section{Cell growth and RNA isolation}

Splicing of pre-35S rRNA transcribed by Pol I was measured using S. cerevisiae strain INVSc2/TtLSU1, grown in YPD medium. Galactose-inducible plasmids were transformed into BY4733 by the LiOAc method (Gietz and Schiestl 1991) and selected at $30^{\circ} \mathrm{C}$ on synthetic complete medium lacking leucine (p425-GAL1 derivative) or uracil (pNOY102 derivatives), and containing $2 \%$ glucose. Liquid cultures of selective media containing $2 \%$ galactose were inoculated with isolated colonies and grown for $30 \mathrm{~h}$ at $30^{\circ} \mathrm{C}\left(\mathrm{OD}_{600}=1.0\right)$ to achieve stable plasmid expression. Cells were harvested at $4^{\circ} \mathrm{C}$ and stored at $-80^{\circ} \mathrm{C}$. Total yeast RNA was purified by two to three extractions with hot acidic phenol/chloroform (Rose et al. 1990). Extracted RNA was precipitated by the addition of $0.3 \mathrm{M}$ sodium acetate ( $\mathrm{pH} 5.0$ ) and 1 volume of $100 \%$ isopropanol. Yield was determined by UV absorption at $260 \mathrm{~nm}$, assuming $40 \mathrm{mg} / \mathrm{mL}=1$ $\mathrm{OD}_{260}$.

\section{Northern blots}

Total RNA $(10 \mu \mathrm{g})$ was denatured with glyoxal and resolved on a 1.4\% agarose gel (1:1 Seakem:NuSieve; FMC). Glyoxal modification reactions $(50 \mu \mathrm{L})$ contained $50 \%$ dimethyl sulfoxide, 10 $\mathrm{mM}$ sodium phosphate $(\mathrm{pH} 7.0)$, and $8 \%$ deionized glyoxal, and were incubated for $1 \mathrm{~h}$ at $50^{\circ} \mathrm{C}$. Prior to loading, $5 \mu \mathrm{L}$ of $50 \%$ glycerol $/ 0.25 \%$ bromophenol blue was added, and the reactions were stored on ice. Following electrophoresis, RNA was transferred to a Nytran nylon membrane (Schleicher \& Schuell) by capillary wicking in $10 \times$ SSPE overnight at room temperature. RNA was immobilized on the membrane by UV cross-linking (120 mJ; UV Stratalinker). Following cross-linking, the membrane was washed twice in $40 \mathrm{mM}$ Tris- $\mathrm{HCl}(\mathrm{pH} 8.0)$ to remove the glyoxal modifications from the RNA.

Oligonucleotide probes complementary to the Tetrahymena group I intron (5'-GGCTGTTGACCCCTTTCCCGCAATTTGA CGGTCTTGCCTTTTAAACCGATGCAATCTATTGGTTTA), yeast actin mRNA (5'-GGCAATACCTGGGAACATGGTGGTAC), or 25S rRNA “Tag” (5'-ACTCGAGAGCTTCAGTAC) (Peculis and Greer 1998) were labeled with $\left[\gamma^{-}{ }^{32} \mathrm{P}\right] \mathrm{ATP}$ and T4 polynucleotide kinase (NEB) and passed through a TE-10 Chromaspin column (Clontech). Probes were hybridized with the membrane overnight at $45^{\circ} \mathrm{C}$ in $1 \times$ hybridization buffer (Images kit; USB), washed twice for $5 \mathrm{~min}$ each at room temperature in $2 \times \mathrm{SSC} / 0.1 \%$ SDS, once for $15 \mathrm{~min}$ at room temperature in $2 \times \mathrm{SSC} / 0.5 \%$ SDS, twice for $15 \mathrm{~min}$ at $55^{\circ} \mathrm{C}$ in $0.2 \times \mathrm{SSC} / 0.1 \%$ SDS, and twice for $5 \mathrm{~min}$ at room temperature in $2 \times \mathrm{SSC}$. The membrane was exposed to a PhosphorImager screen for $14 \mathrm{~h}$ and quantified using ImageQuant software. 


\section{Quantitation of intron RNA at steady state}

The intensities of the intron, pre-rRNA, and rRNA bands in each lane of Northern blots were normalized to an actin mRNA control. The ratio of spliced intron to pre-rRNA at steady-state,

$$
\frac{[\mathrm{IVS}]_{S S}}{[\text { pre }]_{S S}}=\frac{\text { counts IVS }}{\text { counts pre }},
$$

was taken from the average of RNA samples from two or more transformants, as described above. Because the spliced intron is abundant in INVSc2/TtLSU1 and BY4733/pNOY102-IVS, the amounts of intron and pre-rRNA in these samples were obtained from standard curves as follows: 2.5-20 $\mu \mathrm{g}$ of each total yeast RNA sample was loaded on agarose gels and analyzed as described above. For each RNA species, the best leastsquares fit to counts versus micrograms of total RNA over the concentration range giving a linear change in intensity was used to calculate the intensity (counts) corresponding to $10 \mu \mathrm{g}$ of RNA. These corrected intensities were then used to calculate the ratio of intron to pre-rRNA. For GAL-IVS-GFP, actin mRNA was not used as a control because it co-migrates with the pre-RNA.

\section{RNA decay rates}

Transformed yeast were grown in $150 \mathrm{~mL}$ of selective galactose medium for $30 \mathrm{~h}$ as described above. The cells were harvested and resuspended in $15 \mathrm{~mL}$ of minimal medium with $2 \%$ glucose at $30^{\circ} \mathrm{C}$ to prevent further transcription from the GAL promoter (Parker et al. 1991). Aliquots ( $1 \mathrm{~mL}$ ) were harvested at various times by spinning in a microcentrifuge for $10 \mathrm{sec}$ at $14,000 \mathrm{~g}$. Cell pellets were immediately frozen in aluminum racks pre-chilled to $-76^{\circ} \mathrm{C}$ (dry ice). Total RNA was isolated and analyzed by Northern hybridization as described above. The fraction of spliced intron or pre-rRNA relative to actin mRNA at each time was normalized to the level of steady-state expression before the addition of glucose and fit to a first-order rate equation,

$$
[R N A](t)=[R N A]_{S S} \exp \left(-k_{o b s} t\right)
$$

\section{Splicing partition factor}

The partition factor or fraction of active RNA, $\Phi$, was calculated from Equation 1, rewritten as

$$
\Phi=\alpha /(1+\alpha)
$$

in which

$$
\alpha=\frac{[I V S]_{S S}}{[\text { pre }]_{S S}} \bullet \frac{k_{d, I V S}}{k_{d, p r e}}
$$

and $k_{d \text {,pre }}$ and $k_{d, \mathrm{IVs}}$ are the decay rates for the unspliced inactive precursor and spliced intron RNA, respectively (Koduvayur and Woodson 2004). The average decay rate of the free intron was $0.015 \mathrm{~min}^{-1}$.

\section{ACKNOWLEDGMENTS}

We thank M. Nomura, B. Peculis, and J. Boeke for reagents and helpful advice; and R. Moss for technical assistance. This work was supported by a grant from the NIH (GM46886).

Received June 8, 2006; accepted September 14, 2006.

\section{REFERENCES}

Allmang, C., Mitchell, P., Petfalski, E., and Tollervey, D. 2000. Degradation of ribosomal RNA precursors by the exosome. Nucleic Acids Res. 28: 1684-1691.

Andersen, J.B., Sternberg, C., Poulsen, L.K., Bjorn, S.P., Givskov, M., and Molin, S. 1998. New unstable variants of green fluorescent protein for studies of transient gene expression in bacteria. Appl. Environ. Microbiol. 64: 2240-2246.

Bass, B.L. and Cech, T.R. 1984. Specific interaction between the self-splicing RNA of Tetrahymena and its guanosine substrate: Implications for biological catalysis by RNA. Nature 308: $820-826$.

Bentley, D.L. 2005. Rules of engagement: Co-transcriptional recruitment of pre-mRNA processing factors. Curr. Opin. Cell Biol. 17: 251-256.

Brehm, S.L. and Cech, T.R. 1983. Fate of an intervening sequence ribonucleic acid: Excision and cyclization of the Tetrahymena ribosomal ribonucleic acid intervening sequence in vivo. Biochemistry 22: 2390-2397.

Brion, P., Schroeder, R., Michel, F., and Westhof, E. 1999. Influence of specific mutations on the thermal stability of the td group I intron in vitro and on its splicing efficiency in vivo: A comparative study. RNA 5: 947-958.

Byun, J., Lan, N., Long, M., and Sullenger, B.A. 2003. Efficient and specific repair of sickle $\beta$-globin RNA by trans-splicing ribozymes. RNA 9: 1254-1263.

Cannone, J.J., Subramanian, S., Schnare, M.N., Collett, J.R., D'Souza, L.M., Du, Y., Feng, B., Lin, N., Madabusi, L.V., Muller, K.M., et al. 2002. The Comparative RNA Web (CRW) site: An online database of comparative sequence and structure information for ribosomal, intron, and other RNAs. BMC Bioinformatics 3: 2.

Cate, J.H., Yusupov, M.M., Yusupova, G.Z., Earnest, T.N., and Noller, H.F. 1999. X-ray crystal structures of $70 \mathrm{~S}$ ribosome functional complexes. Science 285: 2095-2104.

Cech, T.R. 1990. Self-splicing of group I introns. Annu. Rev. Biochem. 59: 543-568.

Cech, T.R. and Rio, D.C. 1979. Localization of transcribed regions on extrachromosomal ribosomal RNA genes of Tetrahymena thermophila by R-loop mapping. Proc. Natl. Acad. Sci. 76: 5051-5055.

Chakshusmathi, G., Kim, S.D., Rubinson, D.A., and Wolin, S.L. 2003. A La protein requirement for efficient pre-tRNA folding. EMBO J. 22: $6562-6572$.

Dammel, C.S. and Noller, H.F. 1993. A cold-sensitive mutation in $16 S$ rRNA provides evidence for helical switching in ribosome assembly. Genes \& Dev. 7: 660-670.

de la Cruz, J., Kressler, D., Rojo, M., Tollervey, D., and Linder, P. 1998. Spb4p, an essential putative RNA helicase, is required for a late step in the assembly of $60 \mathrm{~S}$ ribosomal subunits in Saccharomyces cerevisiae. RNA 4: 1268-1281.

Diegelman-Parente, A. and Bevilacqua, P.C. 2002. A mechanistic framework for co-transcriptional folding of the HDV genomic ribozyme in the presence of downstream sequence. J. Mol. Biol. 324: $1-16$.

Din, N., Engberg, J., Kaffenberger, W., and Eckert, W.A. 1979. The intervening sequence in the $26 \mathrm{~S}$ rRNA coding region of T. thermophila is transcribed within the largest stable precursor for rRNA. Cell 18: 525-532. 
Donahue, C.P. and Fedor, M.J. 1997. Kinetics of hairpin ribozyme cleavage in yeast. RNA 3: 961-973.

Donahue, C.P., Yadava, R.S., Nesbitt, S.M., and Fedor, M.J. 2000. The kinetic mechanism of the hairpin ribozyme in vivo: Influence of RNA helix stability on intracellular cleavage kinetics. J. Mol. Biol. 295: 693-707.

Dreyfuss, G., Kim, V.N., and Kataoka, N. 2002. Messenger-RNAbinding proteins and the messages they carry. Nat. Rev. Mol. Cell Biol. 3: 195-205.

Emerick, V.L. and Woodson, S.A. 1993. Self-splicing of the Tetrahymena pre-rRNA is decreased by misfolding during transcription. Biochemistry 32: 14062-14067.

Emerick, V.L., Pan, J., and Woodson, S.A. 1996. Analysis of ratedetermining conformational changes during self-splicing of the Tetrahymena intron. Biochemistry 35: 13469-13477.

Fan, H., Goodier, J.L., Chamberlain, J.R., Engelke, D.R., and Maraia, R.J. 1998. $5^{\prime}$ processing of tRNA precursors can be modulated by the human La antigen phosphoprotein. Mol. Cell. Biol. 18: 3201-3211.

Fatica, A. and Tollervey, D. 2002. Making ribosomes. Curr. Opin. Cell Biol. 14: 313-318.

Gietz, R.D. and Schiestl, R.H. 1991. Applications of high efficiency lithium acetate transformation of intact yeast cells using singlestranded nucleic acids as carrier. Yeast 7: 253-263.

Granneman, S. and Baserga, S.J. 2005. Crosstalk in gene expression: Coupling and co-regulation of rDNA transcription, pre-ribosome assembly and pre-rRNA processing. Curr. Opin. Cell Biol. 17: 281-286.

Grossberger, R., Mayer, O., Waldsich, C., Semrad, K., Urschitz, S., and Schroeder, R. 2005. Influence of RNA structural stability on the RNA chaperone activity of the Escherichia coli protein StpA. Nucleic Acids Res. 33: 2280-2289.

Hagen, M. and Cech, T.R. 1999. Self-splicing of the Tetrahymena intron from mRNA in mammalian cells. EMBO J. 18: 64916500.

Heilman-Miller, S.L. and Woodson, S.A. 2003. Effect of transcription on folding of the Tetrahymena ribozyme. RNA 9: 722-733.

Jackson, S., Cannone, J., Lee, J., Gutell, R., and Woodson, S. 2002. Distribution of rRNA introns in the three-dimensional structure of the ribosome. J. Mol. Biol. 323: 35-52.

Koduvayur, S.P. and Woodson, S.A. 2004. Intracellular folding of the Tetrahymena group I intron depends on exon sequence and promoter choice. RNA 10: 1526-1532.

Kressler, D., Linder, P., and de La Cruz, J. 1999. Protein trans-acting factors involved in ribosome biogenesis in Saccharomyces cerevisiae. Mol. Cell. Biol. 19: 7897-7912.

Laederach, A., Shcherbakova, I., Liang, M.P., Brenowitz, M., and Altman, R.B. 2006. Local kinetic measures of macromolecular structure reveal partitioning among multiple parallel pathways from the earliest steps in the folding of a large RNA molecule. J. Mol. Biol. 358: 1179-1190.

Lin, J. and Vogt, V.M. 1998. I-PpoI, the endonuclease encoded by the group I intron PpLSU3, is expressed from an RNA polymerase I transcript. Mol. Cell. Biol. 18: 5809-5817.

Long, M.B. and Sullenger, B.A. 1999. Evaluating group I intron catalytic efficiency in mammalian cells. Mol. Cell. Biol. 19: 6479-6487.

Mahen, E.M., Harger, J.W., Calderon, E.M., and Fedor, M.J. 2005. Kinetics and thermodynamics make different contributions to RNA folding in vitro and in yeast. Mol. Cell 19: 27-37.

Mumberg, F., Muller, R., and Funk, M. 1995. Yeast vectors for the controlled expression of heterologous proteins in different genetic backgrounds. Gene 156: 119-122.

Neugebauer, K.M. 2002. On the importance of being co-transcriptional. J. Cell Sci. 115: 3865-3871.

Nikolcheva, T. and Woodson, S.A. 1999. Facilitation of group I splicing in vivo: Misfolding of the Tetrahymena IVS and the role of ribosomal RNA exons. J. Mol. Biol. 292: 557-567.
Nogi, Y., Yano, R., and Nomura, M. 1991. Synthesis of large rRNAs by RNA polymerase II in mutants of Saccharomyces cerevisiae defective in RNA polymerase I. Proc. Natl. Acad. Sci. 88: 3962-3966.

Nogi, Y., Yano, R., Dodd, J., Carles, C., and Nomura, M. 1993. Gene RRN4 in Saccharomyces cerevisiae encodes the A12.2 subunit of RNA polymerase I and is essential only at high temperatures. Mol. Cell. Biol. 13: 114-122.

Oakes, M., Nogi, Y., Clark, M.W., and Nomura, M. 1993. Structural alterations of the nucleolus in mutants of Saccharomyces cerevisiae defective in RNA polymerase I. Mol. Cell. Biol. 13: 24412455.

Pan, T. and Sosnick, T. 2006. RNA folding during transcription. Annu. Rev. Biophys. Biomol. Struct. 35: 161-175.

Pan, J. and Woodson, S.A. 1998. Folding intermediates of a selfsplicing RNA: Mispairing of the catalytic core. J. Mol. Biol. 280: 597-609.

Pan, J. and Woodson, S.A. 1999. The effect of long-range loop-loop interactions on folding of the Tetrahymena self-splicing RNA. J. Mol. Biol. 294: 955-965.

Pan, J., Thirumalai, D., and Woodson, S.A. 1997. Folding of RNA involves parallel pathways. J. Mol. Biol. 273: 7-13.

Pan, J., Thirumalai, D., and Woodson, S.A. 1999a. Magnesiumdependent folding of self-splicing RNA: Exploring the link between cooperativity, thermodynamics, and kinetics. Proc. Natl. Acad. Sci. 96: 6149-6154.

Pan, T., Artsimovitch, I., Fang, X.W., Landick, R., and Sosnick, T.R. 1999b. Folding of a large ribozyme during transcription and the effect of the elongation factor NusA. Proc. Natl. Acad. Sci. 96: 9545-9550.

Pan, J., Deras, M.L., and Woodson, S.A. 2000. Fast folding of a ribozyme by stabilizing core interactions: Evidence for multiple folding pathways in RNA. J. Mol. Biol. 296: 133-144.

Pannone, B.K., Xue, D.H., and Wolin, S.L. 1998. A role for the yeast La protein in U6 snRNP assembly: Evidence that the La protein is a molecular chaperone for RNA polymerase III transcripts. EMBO J. 17: 7442-7453.

Parker, R., Herrick, D., Peltz, S.W., and Jacobson, A. 1991. Measurement of mRNA decay rates in Saccharomyces cerevisiae. Methods Enzymol. 194: 415-423.

Peculis, B.A. and Greer, C.L. 1998. The structure of the ITS2-proximal stem is required for pre-rRNA processing in yeast. RNA 4: 16101622.

Poot, R.A., Tsareva, N.V., Boni, I.V., and van Duin, J. 1997. RNA folding kinetics regulates translation of phage MS2 maturation gene. Proc. Natl. Acad. Sci. 94: 10110-10115.

Ronen, M. and Botstein, D. 2006. Transcriptional response of steadystate yeast cultures to transient perturbations in carbon source. Proc. Natl. Acad. Sci. 103: 389-394.

Rose, M.D., Winston, F., Hieter, P., and Sherman, F. 1990. Methods in yeast genetics: A laboratory course manual. Cold Spring Harbor Laboratory Press, Cold Spring Harbor NY.

Russell, R., Zhuang, X., Babcock, H.P., Millett, I.S., Doniach, S., Chu, S., and Herschlag, D. 2002. Exploring the folding landscape of a structured RNA. Proc. Natl. Acad. Sci. 99: 155-160.

Schroeder, R., Barta, A., and Semrad, K. 2004. Strategies for RNA folding and assembly. Nat. Rev. Mol. Cell Biol. 5: 908-919.

Tharun, S., He, W., Mayes, A.E., Lennertz, P., Beggs, J.D., and Parker, R. 2000. Yeast Sm-like proteins function in mRNA decapping and decay. Nature 404: 515-518.

Thirumalai, D. and Woodson, S.A. 1996. Kinetics of folding of protein and RNA. Acc. Chem. Res. 29: 433-439.

Treiber, D.K. and Williamson, J.R. 1999. Exposing the kinetic traps in RNA folding. Curr. Opin. Struct. Biol. 9: 339-345.

Uhlenbeck, O.C. 1995. Keeping RNA happy. RNA 1: 4-6.

Waldsich, C., Grossberger, R., and Schroeder, R. 2002. RNA chaperone StpA loosens interactions of the tertiary structure in the td group I intron in vivo. Genes \& Dev. 16: 2300-2312. 
Wickiser, J.K., Winkler, W.C., Breaker, R.R., and Crothers, D.M. 2005. The speed of RNA transcription and metabolite binding kinetics operate an FMN riboswitch. Mol. Cell 18: 49-60.

Woodson, S.A. 1992. Exon sequences distant from the splice junction are required for efficient self-splicing of the Tetrahymena IVS. Nucleic Acids Res. 20: 4027-4032.

Woodson, S.A. 2000. Recent insights on RNA folding mechanisms from catalytic RNA. Cell. Mol. Life Sci. 57: 796-808.

Zarrinkar, P.P. and Williamson, J.R. 1996. The kinetic folding pathway of the Tetrahymena ribozyme reveals possible similarities between RNA and protein folding. Nat. Struct. Biol. 3: 432-438.
Zavanelli, M.I., Britton, J.S., Igel, A.H., and Ares Jr., M. 1994. Mutations in an essential U2 small nuclear RNA structure cause cold-sensitive U2 small nuclear ribonucleoprotein function by favoring competing alternative U2 RNA structures. Mol. Cell. Biol. 14: 1689-1697.

Zhang, F., Ramsay, E.S., and Woodson, S.A. 1995. In vivo facilitation of Tetrahymena group I intron splicing in Escherichia coli preribosomal RNA. RNA 1: 284-292.

Zhuang, X., Bartley, L.E., Babcock, H.P., Russell, R., Ha, T., Herschlag, D., and Chu, S. 2000. A single-molecule study of RNA catalysis and folding. Science 288: 2048-2051. 

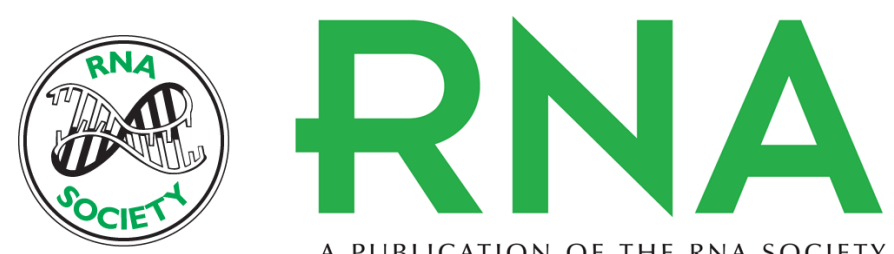

A PUBLICATION OF THE RNA SOCIETY

\title{
Self-splicing of a group I intron reveals partitioning of native and misfolded RNA populations in yeast
}

\author{
Scott A. Jackson, Sujatha Koduvayur and Sarah A. Woodson
}

RNA 2006 12: 2149-2159 originally published online October 24, 2006

Access the most recent version at doi:10.1261/rna.184206

\section{References This article cites 67 articles, 30 of which can be accessed free at: \\ http://rnajournal.cshlp.org/content/12/12/2149.full.html\#ref-list-1}

\section{License}
Email Alerting Receive free email alerts when new articles cite this article - sign up in the box at the Service top right corner of the article or click here.

To subscribe to RNA go to:

http://rnajournal.cshlp.org/subscriptions 